\title{
ESPECIALIZAÇÃO EM SAÚDE DA FAMÍLIA PARA ENFERMEIROS
}

\author{
José Vitor da Silva ${ }^{1}$ \\ Inácia Maria Rezende Bustamante ${ }^{2}$ \\ Ir. Lucyla Junqueira Carneiro ${ }^{3}$
}

A Escola de Enfermagem Wenceslau Braz (EEWB) da cidade de Itajubá, MG, desde a sua fundação em 1954 assumiu uma filosofia de atenção ao indivíduo, à família e à comunidade e vem mantendo a tradição que possibilita a formação do aluno direcionada em vínculo escola-comunidade, o que se concretiza na área hospitalar e na saúde coletiva (ESCOLA DE ENFERMAGEM WENCESLAU BRAZ, 1998).

Nesta perspectiva, e objetivando atuar não só como órgão formador de profissionais adequados às estratégias do modelo de saúde vigente, a Diretora desta Escola utilizou todos os recursos e esforços necessários à implantação do curso de Especialização em Saúde para Enfermeiros, considerando-se assim pioneira, enquanto escola particular isolada, na criação desse curso.

Para sua estruturação e funcionamento a EEWB inspirou-se no marco conceitual do Curso de Enfermagem Familiar da Universidade de Calgary, Canadá, que consiste em trabalhar com família no enfoque sistêmico, ou seja, com a utilização da Teoria Geral de Sistema, introduzida em 1936 por L. Von Bertalanffly. Tem-se utilizado a referida Teoria de forma crescente no estudo de famílias por parte dos profissionais de saúde e especificamente pelos enfermeiros.

Segundo Allmond, Buckman e Gofman, citados por Wright e Leahey (1987), a Teoria de Sistemas, quando utilizada no estudo de famílias, facilita a compreensão e o significado daquilo que ocorre com as mesmas.

Os estudos com família no Brasil ainda são incipientes, porém o fato de os profissionais de Enfermagem estarem desenvolvendo estudos sobre a percepção das famílias já representa um avanço. Marcom, Carreira e Balan, citados por Marcon e Elsen (1999), encontraram num estudo sobre os resumos de trabalhos apresentados nos Congressos Brasileiros de Enfermagem, no período de 1986 a 1996, que 4,9\% deles estavam relacionados com o tema família. Destacam ainda que os enfermeiros estão conscientes da importância de se valorizar a experiência da própria família ao vivenciar determinadas situações relacionadas ao processo viver-ser-estar saudável e do adoecer, como estratégia para subsidiar o cuidar-assistir a família.

Com isso, a Enfermagem começa a desenvolver sua essência e estabelecer que assistir é muito mais do que curar e cuidar, mesmo que não proporcione a cura. Cuidar, para Leininger(1991), é promover, manter, recuperar a saúde ou criar melhores condições de vida, através de meios que vão além das necessidades físicas, emocionais e sociais do indivíduo, ou seja, existe uma disposição em reproduzir a visão de mundo compatível com o paradigma emergente.

É importante mencionar também que a atenção à família já é uma realidade de diversas profissões que preocupam com o sistema de trabalho, formação e capacitação dos profissionais. A criação do Programa de Saúde da Família (PSF) pelo Ministério da Saúde caracteriza uma preocupação do Estado em voltar suas políticas públicas a este segmento da população, assim como o empenho de manter suas políticas sociais voltadas para o desenvolvimento da vida familiar (Marcone Elsen, 1999).

De acordo ainda com as citadas autoras o PSF "constitui uma estratégia de ação da equipe de

${ }^{1}$ Enfermeiro. Prof. da Escola de Enfermagem Wenceslau Braz de Itajubá, MG e do Departamento de Enfermagem da FACIMPA de Pouso Alegre, MG e Doutorando em Enfermagem pela EEUSP.

2 Enfermeira. Profa ${ }^{\circ}$ da Escola de Enfermagem Wenceslau Braz, Itajubá, MG.

${ }^{3}$ Enfermeira. Prof ${ }^{a}$ e Diretora da Escola de Enfermagem Wenceslau Braz, Itajubá, MG. 
saúde que tem uma proposta substitutiva, ou seja, de reestruturação do modelo de assistência vigente tendo em vista a consolidação de outro tipo de assistência à saúde, traduzido por uma maior integração da equipe de saúde com a população“.

Por outro lado, Friedman (1986) complementa que a capacitação do enfermeiro para atuar com a família é imprescindível. Ele necessita aprofundar mais os seus conhecimentos no sentido de saber abordar a mesma e estar ciente de que a situação de saúde-doença tem um outro enfoque quando interpretado do ponto de vista da família.

Ao se propor e elaborar cursos de especialização em Saúde da Família para enfermeiros como um dos pressupostos fundamentais para consolidação do PSF, se está em consonância com a organização Mundial da Saúde, que os considera e os prescreve como elemento essencial de qualidade do serviço e também de preservação da motivação no trabalho, considerando que os recursos humanos são, ao mesmo tempo, a parte mais importante e mais dispendiosa de um sistema de saúde (SECRETARIA DE ESTADO DA SAÚDE DE MINAS GERAIS, 1996).

Considerando a importância da capacitação do enfermeiro para a atuação profissional junto às famílias, a EEWB estabeleceu as seguintes propostas para o curso de Especialização em Saúde da Família para Enfermeiros:

- Proporcionar o aperfeiçoamento técnico e científico em temas relevantes da área da saúde, como estratégia de identificação dos problemas de saúde da população e recursos para a vigilância de saúde e qualidade da assistência de Enfermagem em nível de prevenção, promoção, reabilitação e restauração.

- Despertar o enfermeiro para atuar no modelo assistencial de saúde e suas conseqüências, apresentando-Ihe o PSF como estratégia de reestruturação do modelo vigente.

- Oferecer capacitação sócio-pedagógica para atuação de educação para a saúde da família.

- Possibilitar a qualificação para a atuação dos enfermeiros por meio da sistematização das ações de Enfermagem em nível familiar.

- Estimular a construção do conhecimento sobre a Enfermagem e a Família através de pesquisa e de referenciais teóricos.

O Curso de Pós-graduação "Lato-Sensu" - Saúde da Família para Enfermeiros da EEWB -tem a duração de 14 meses e carga horária prevista de 550 horas-aula, assim distribuídas:

450 Horas para as partes teórica e prática, 100 horas para os estágios e paralelamente a essas duas etapas, haverá a elaboração e apresentação de monografia por grupos de dois alunos, que abrangerá diversos tipos de estudos, tendo como objeto principal a família. As disciplinas que o constituem são as seguintes: Antropologia da Família, Sociologia da Família, Bioética e Família, Educação para a Saúde da Família, Metodologia do Trabalho Científico, Bioestatística, Políticas de Saúde e SUS, Programa de Saúde da Família (PSF), Saúde da Família, Enfermagem Familiar, Multidisciplinaridade e Família e Estágio.

O mencionado curso, que é de natureza particular, funciona em caráter quinzenal, às sextasfeiras à noite e aos sábados nos períodos da manhã e da tarde. Iniciou a sua primeira turma no mês de maio do ano passado e conta com a previsão de término no mês de julho do corrente ano.

A turma está constituída por 28 enfermeiros procedentes de Itajubá, cidades da região e São Paulo (capital). Predominantemente, trabalham na rede pública e na área de saúde coletiva. Alguns já estão atuando no Programa de Saúde da Família em São João del Rei e Maria da Fé (MG).

Estruturalmente o curso encontra-se fundamentado em quatro eixos principais: no primeiro eixo, são ministradas as disciplinas básicas ou fundamentais (Antropologia, Sociologia e Bioética); posteriormente, $2^{\circ}$ eixo, são apresentadas as disciplinas instrumentais (Educação para a Saúde da Família, Metodologia Científica, Bioestatística, Políticas de Saúde e SUS); no terceiro eixo são desenvolvidas aquelas matérias de natureza específica, constituídas por Saúde da Família, Enfermagem Familiar, Programa de Saúde da Família e Estágio. Finalmente, é oferecida a disciplina complementar (Multidisciplinaridade e Família) que constitui o quarto e último eixo.

"Num mundo caracterizado por mudanças constantes em que a emergência de conhecimentos e a obsolescência dos mesmos se verifica de forma acelerada, entende-se que uma abordagem pedagógica que busque formar, mais do que informar, deve constituir a base, do 
processo educativo. Tal pressuposto encontra respaldo em vários campos de atividades, mormente em relação à área da saúde, na qual se-admite que a apropriação e o trabalho coletivo de construção do saber e do fazer vêm sendo encarados como espaços privilegiados quando confrontados com a apropriação dos mesmos, em nível individual "(SECRETARIA DE ESTADO DA SAÚDE DE MINAS GERAIS, 1996).

Fundamentado nessa afirmativa, o educando do curso em questão não é visto como mero objeto, mas considerado com a riqueza de suas experiências de vida pessoal e profissional. Ele é o sujeito de sua própria aprendizagem e agente capacitado para transformar a sua própria realidade.

$\mathrm{Na}$ sua concepção geral, o curso se baseia em pressupostos da pedagogia de ensino que adota estrategicamente diversas opções metodológicas, de acordo com a exigência da estruturação de seus conteúdos, de forma que as referidas opções se interajam, possibilitando maior êxito no processo ensino-aprendizagem.

A diversificação metodológica utilizada no curso visa também tornar o aluno constantemente ativo, observador e motivado para perceber os problemas da sua realidade em conjunto com a população, e assim estabelecerem metas e prioridades na busca de soluções para problemas comuns.

Conta-se atualmente com o período de nove meses de funcionamento do curso. Diante disso as experiências e os resultados obtidos ainda são muito restritos e inconclusivos. Entretanto, já sepode observar entre os alunos uma nova visão sobre família e a inserção da mesma como objeto de trabalho na atuação profissional. É freqüente nos contatos mantidos com eles o posicionamento de que a família não é um recipiente passivo do cuidado profissional mas sim um agente, sujeito do seu próprio processo de viver.

É importante ressaltar, ainda, que os alunos já expressam o quanto têm aprendido a compreender, respeitar e trabalhar com as famílias. Já constatam que para muitas famílias o direito a uma vida com qualidade e dignidade the é negado e, mais que isso, tampouco são esclarecidos os seus direitos sociais. Contudo espera-se que, até a conclusão do curso, a educação no interior do grupo seja um processo muito especial de ser vivido. A diferença de idades, formação, visões de mundo, conhecimento, objetivos e experiência fará o grupo se sentir muito vivo, constantemente se questionando, avaliando, dando sugestões e se apoiando.

Finalmente, cumpre reconhecer que capacitar-se e trabalhar com famílias é uma das maiores necessidades da Enfermagem e uma estratégia disponível para a obtenção de melhores resultados na área de saúde.

Aos profissionais da saúde, e em especial ao enfermeiro, resta o compromisso, ético inclusive, de buscarem ou então atualizarem os seus conhecimentos e concomitantemente se instrumentalizarem para assistir com competência a este "novo" objeto de cuidado: a família que tanto carece de assistência ou de indicadores necessários para cuidar de seus membros e desta forma alcançar o viver-serestar- saudável em um mundo em transformação (Marcon e Elsen, 1999).

\section{REFERÊNCIAS BIBLIOGRÁFICAS}

ESCOLA DE ENFERMAGEM WENCESLAU BRAZ. Proposta para instalação e funcionamento do Polo de Capacitação, Formação e Educação Permanente de Pessoal para Saúde da Família, Itajubá, 1998.

LEININGER, M. Culture Care Diversity and Universality: A Theory of Nursing. New York: National League for Nursing, 1991.

MARCON, S. S.; ELSEN, I. A Enfermagem com um novo olhar... a necessidade de enxergar a família. Rev. Família, Saúde e Desenvolvimento, Curitiba, v.1, n.1/2, p. 21-26, jan./dez.1999.

FRIEDMAN, M. Family Nursing. Connecticut: Appleton Century Crofts, 1986.

SECRETARIA DE ESTADO DA SAÚDE DE MINAS GERAIS. Educação Permanente em Saúde da Família. Belo Horizonte, 1996.

WRIGHT, L.M.; LEAHEY, M. Nurses and Family. Calgary: F. Davis Company, 1987. 